\title{
Online Banking Security Analysis based on STRIDE Threat Model
}

\author{
Tong Xin and Ban Xiaofang \\ Department of Information Systems Evaluation China Information Technology \\ Security Evaluation Center, Beijing, China \\ tongxin2030@163.com
}

\begin{abstract}
This paper refers important issues regarding how to evaluate the security threats of the online banking effectively, a system threat analysis method combining STRIDE threat model and threat tree analysis is proposed, which improves the efficiency of the threat analysis greatly and also has good practicability. By applying this method to the online banking system threat analysis, we construct STRIDE threat model on the analysis of the key business data, and then we construct threat tree on the security threat by layer-by-layer decomposition. Thus it gives a detailed threat analysis of the online banking system. This security threat analysis has important significance for the online banking system security analysis and for revealing the threats that the online banking facing.
\end{abstract}

Keywords: Threat modeling; Data flow diagrams; online banking; STRIDE threat model; data stream; threat tree

\section{Introduction}

On the basis of security trends and developments of the last decade, where vulnerabilities and incidents reported have increased significantly and attacks are constantly getting more sophisticated while requiring less intruder knowledge [5], innovative threat evaluation techniques for systems and software are needed. In the last few years, several innovative approaches to threat modeling have emerged.

Online banking has been adopted more regularly to support and enhance the performance of the banking industry operations and management. Online banking systems provide us with easy access to banking services. Via a more sophisticated and user-friendly interface, a browser or a dedicated standalone application, people can use the Internet to connect to the bank's computer system. This increasing trend has meant that security issues of confidentiality, integrity, and privacy have become progressively more serious in online banking systems to both the banks and customers. Study on risk evaluation and threat mining of online banking system have received widespread attention $[1,2,6]$.

This paper discusses the security of today's online banking systems. We present a system threat analysis method which combines the STRIDE threat model and threat tree analysis. Through applying this threat analysis method to the online banking system threats analysis, we construct the online banking system threat model. Firstly, we analyze the key business online banking system data flow diagram, and then by constructing STRIDE threat model to identify the threats, and through the establishment of threat tree reducing gradually the complexity of threat analysis of online banking system. It is of important significance to the security analysis and risk evaluation of online banking system, and to deeply mining vulnerabilities and risks of online banking system. 
This paper is organized as follows. Section 2, we decompose the data flow of the online banking system by using the data flow diagram. In Section 3 we analyze the online banking threat based on STRIDE model. And then the method of constructing a threat tree is shown in Section 4. The last section concludes the paper.

\section{Data Flow Analysis of Online Banking System}

According to the difference of business process operations, we divide the online banking business process into different data streams: processing, transmission, and information storage. In this section, we use the data flow diagram to describe the online banking business process in detail.

\subsection{Representation of Data Flow Diagram}

In threat modeling analysis, the data flow diagram (DFD) is usually used to reflect the data flow interaction relationship between online banking system and external interactors. The symbols of data flow diagram are shown in Table 1.

Table 1. Data Flow Diagram Symbols

\begin{tabular}{|c|c|c|}
\hline Symbol & Elements Name & Description \\
\hline \hline & External Interactor & Input to the system \\
\hline & Process & Transforms or manipulates data \\
\hline & Multiple Process & Transforms or manipulates data \\
\hline & Data Storage & Location that stores temporary or permanent data \\
\hline & Data Flow & Depicts data flow from data stores, processes or interactors \\
\hline & Boundary & Machine, physical, address space or trust boundary. \\
\hline
\end{tabular}

\subsection{Analysis of the Online Banking System}

The online banking system is a system that provides online banking services for customers, and is also a system that exposed to the Internet environment. The external interactors of online banking system mainly include:

Online banking client (1.0): can request to the online banking system, anything that can be making the request to the online banking system, such as the browser and contract etc.

B2B/B2C system (2.0): can request to the online banking system, including the third party electronic payment platform and agency payment platform.

The management stuff (3.0): can be initiated by management operation request to the online banking system, online banking system to provide the corresponding management interface for management personnel to carry on the management to the online banking system, such as log audit.

Core bank account system (4.0): Suppose the online banking internal network environment and itslf are credible.

The main business of online banking can be divided into: Login (5.1), query type of transactions (5.2), set type of transactions (5.3), transfer type of transactions (5.4), electronic 
payment (5.5), asset/cash changing transactions (5.6) and system management (5.7). The first level dada flow diagram decomposition of these business process operations is shown in Figure 1.

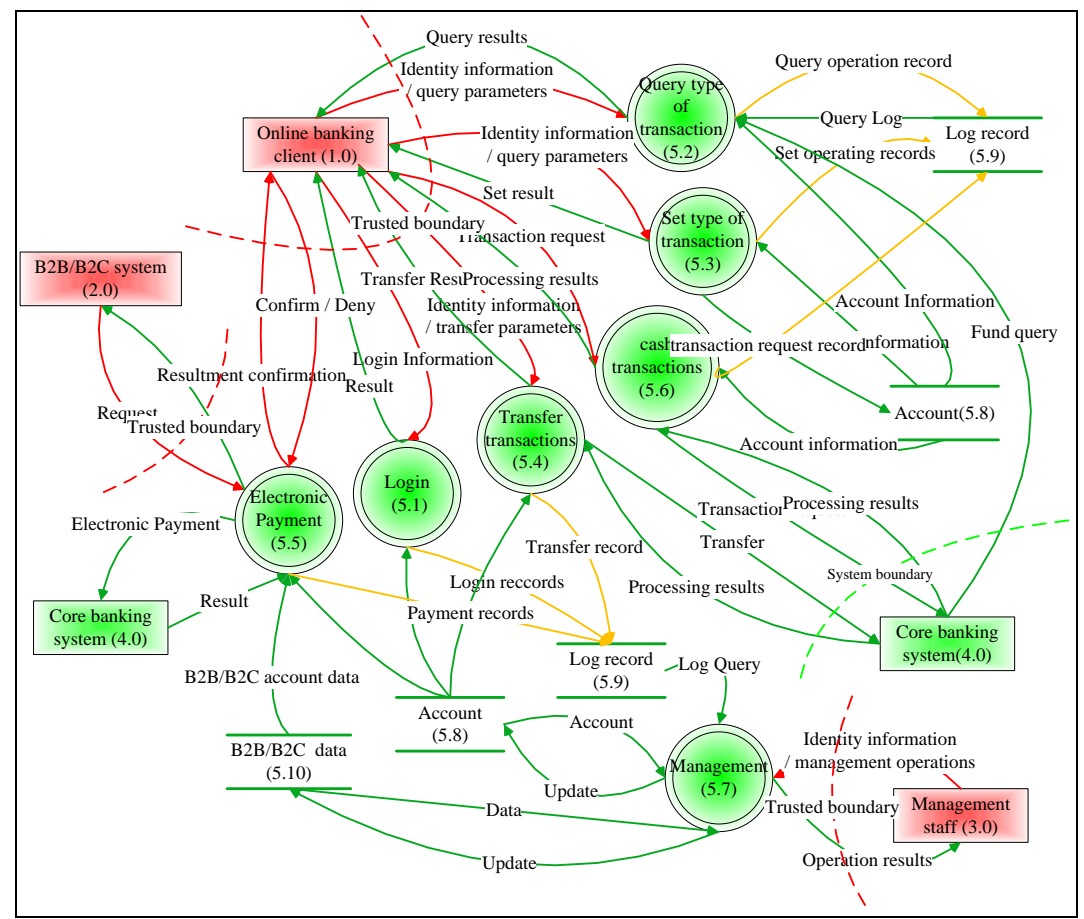

Figure 1. Critical Business Data Flow Diagram

Figure 2- Figure 8 give the 2 nd level data flow diagram decomposition of the above 7 types business operation, respectively.

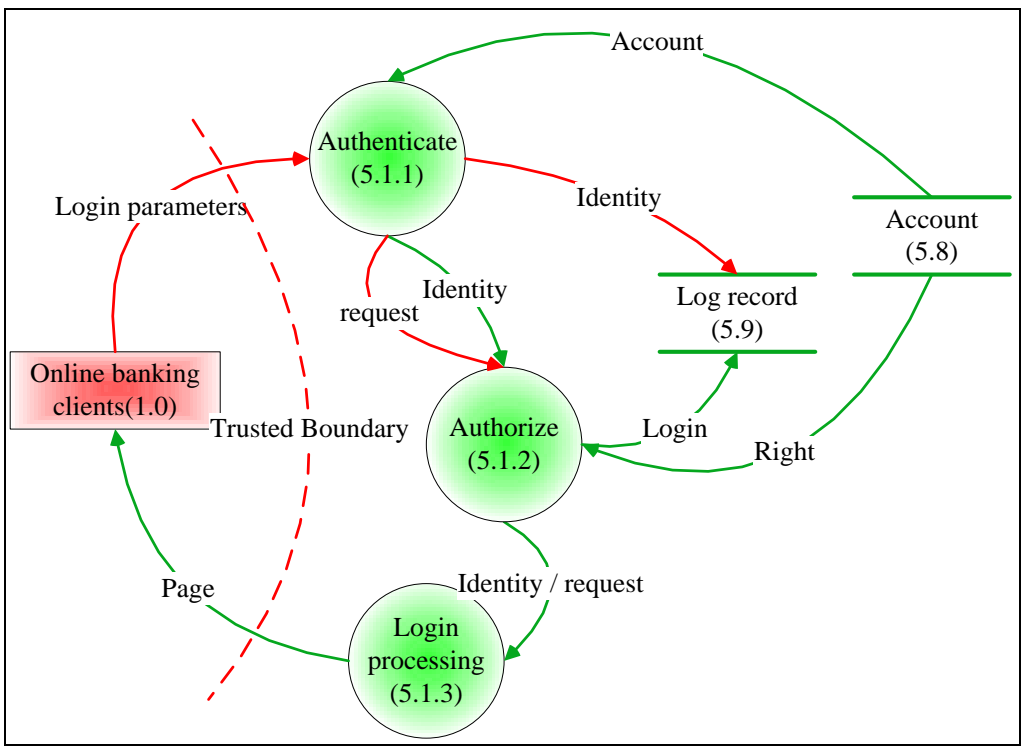

Figure 2. Login Process 


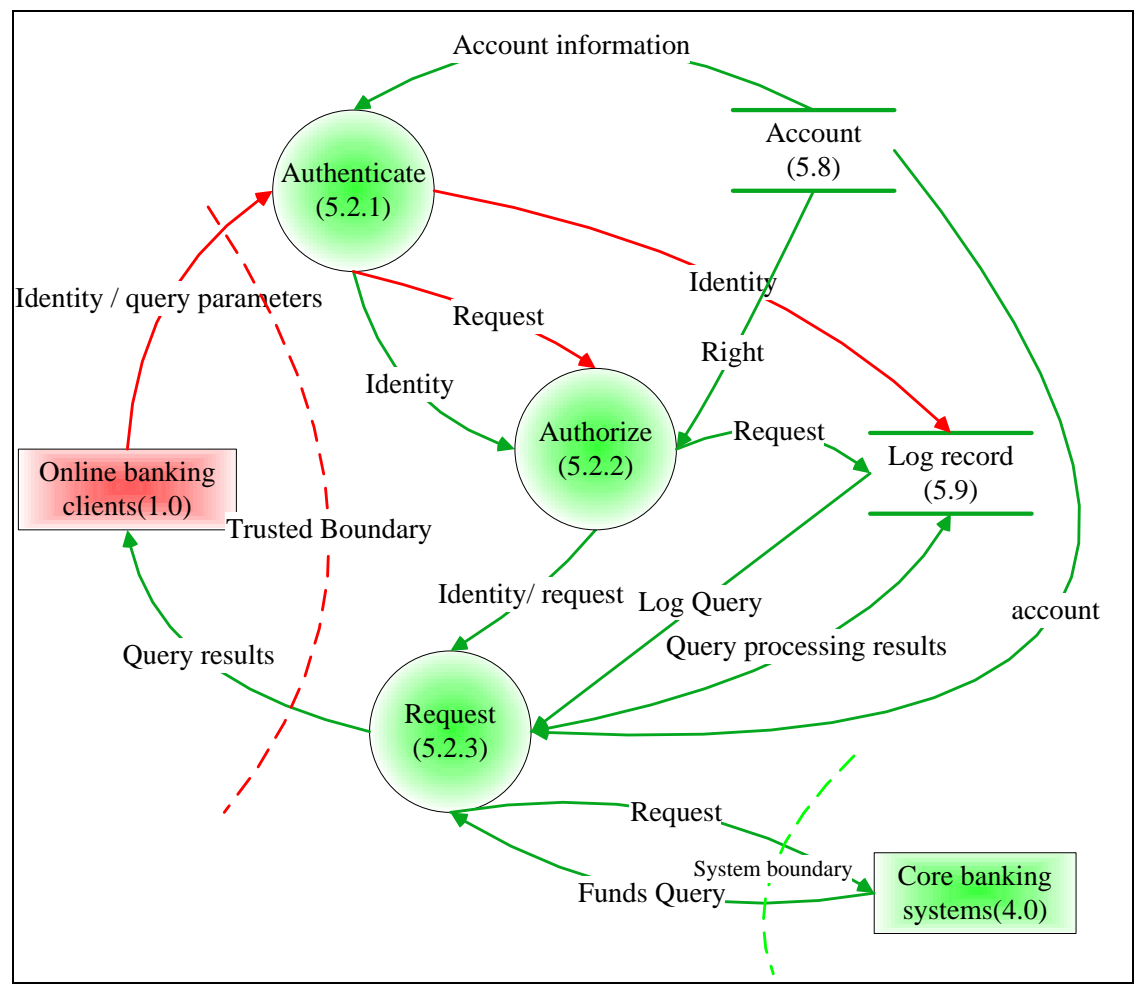

Figure 3. Query Type of Transactions Process

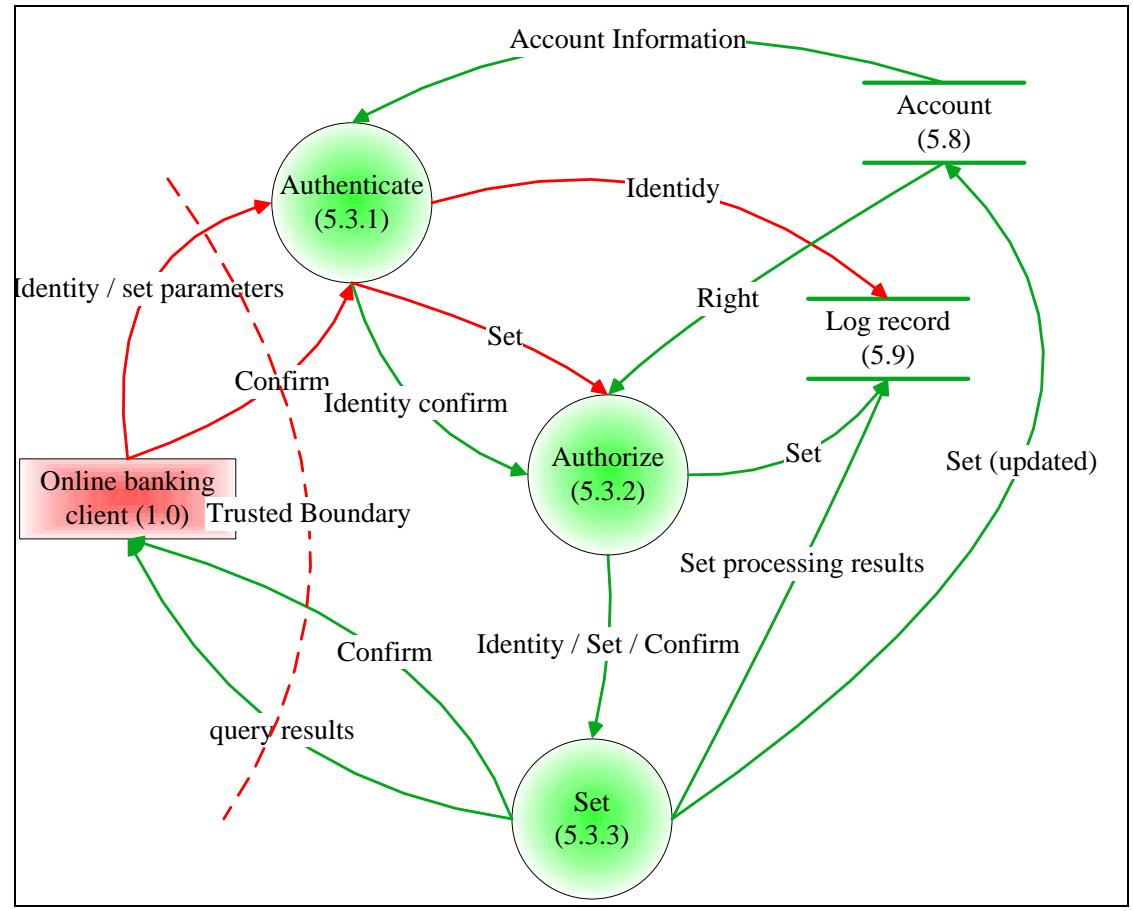

Figure 4. Set Type of Transaction Process 


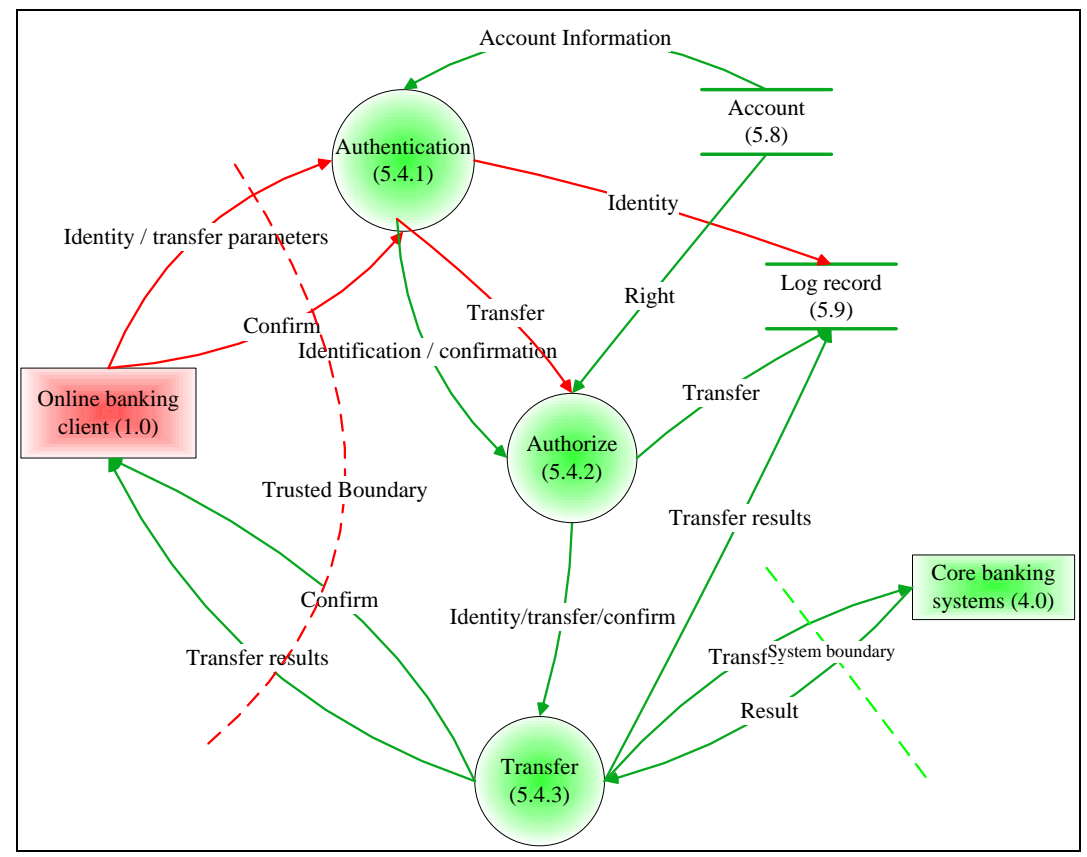

Figure 5. Transfer Type of Transaction Process

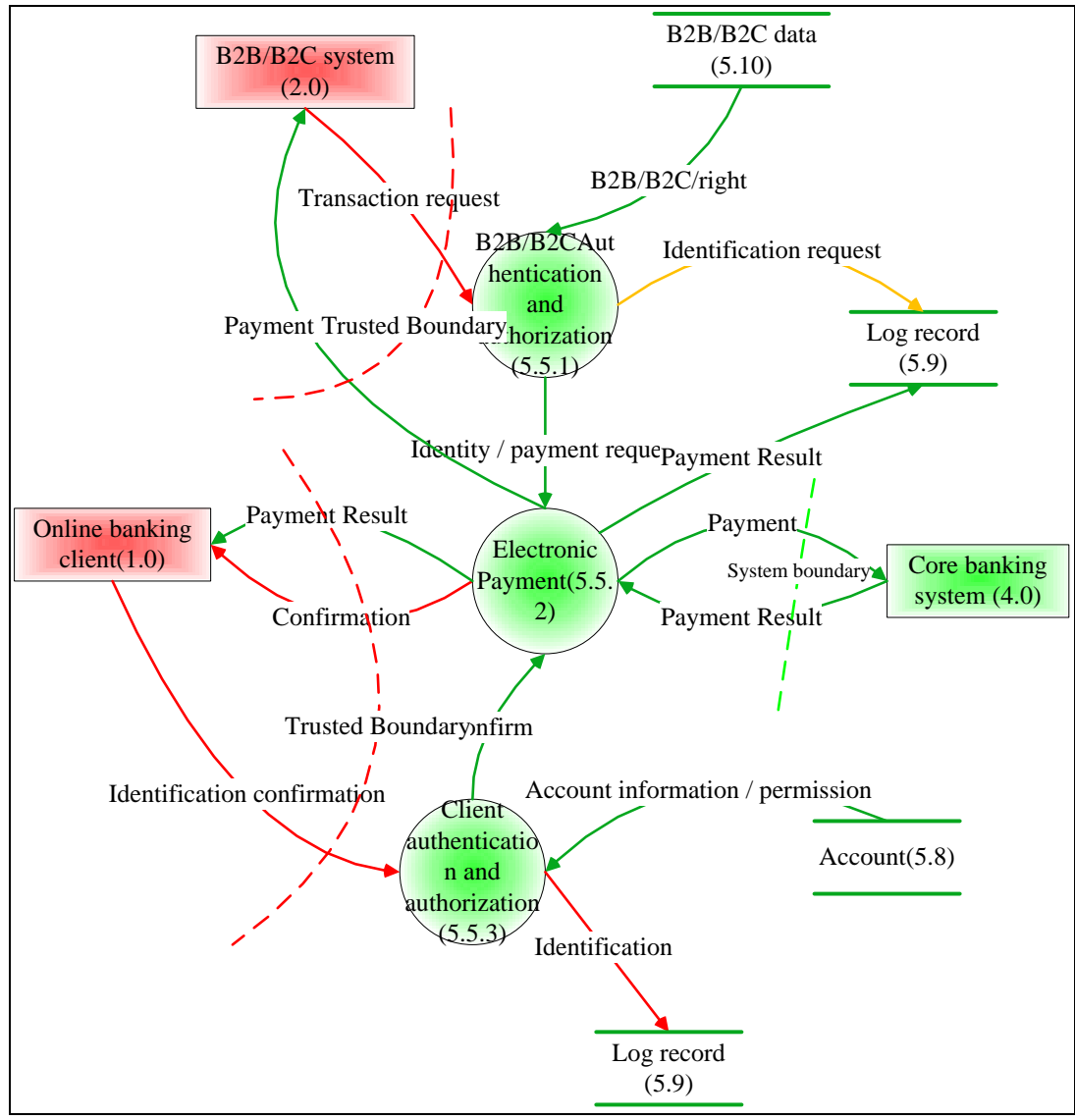

Figure 6. Electronic Payment Process 


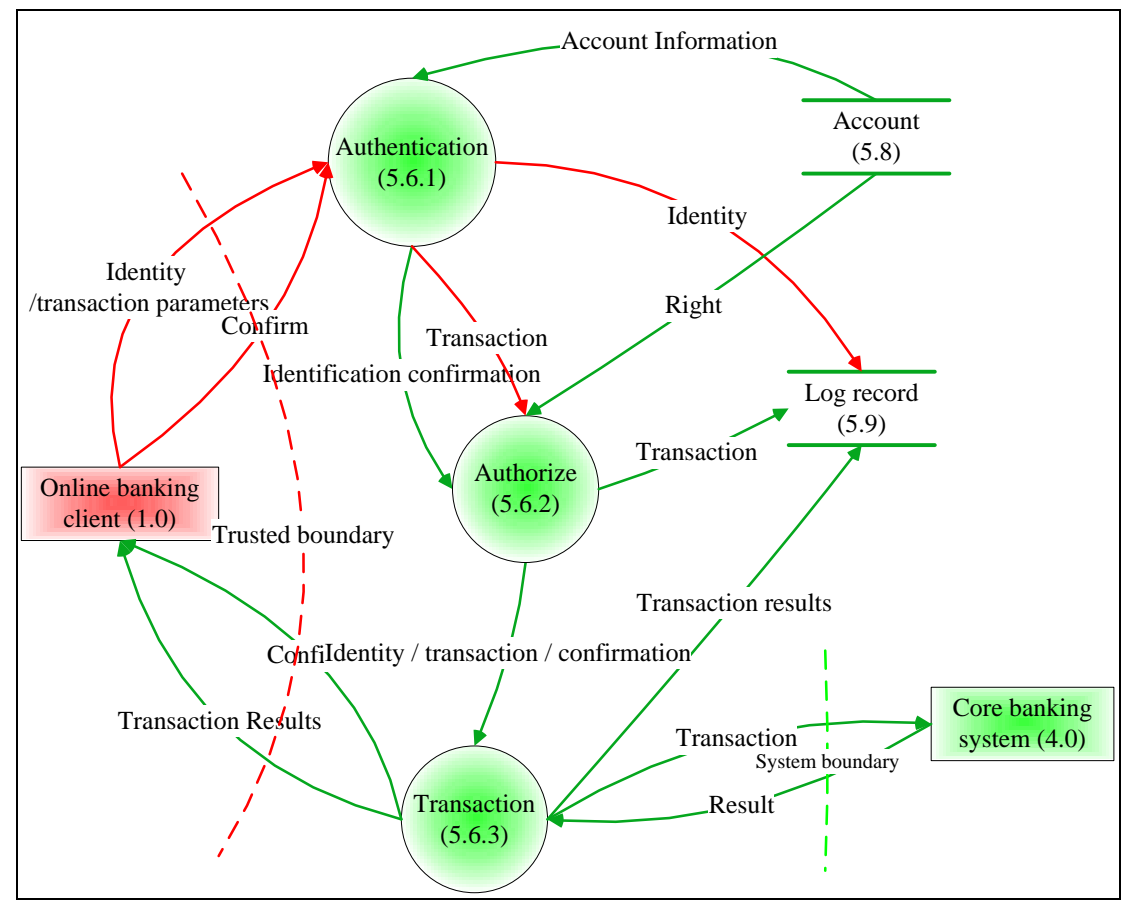

Figure 7. Assets/cash Changing Process

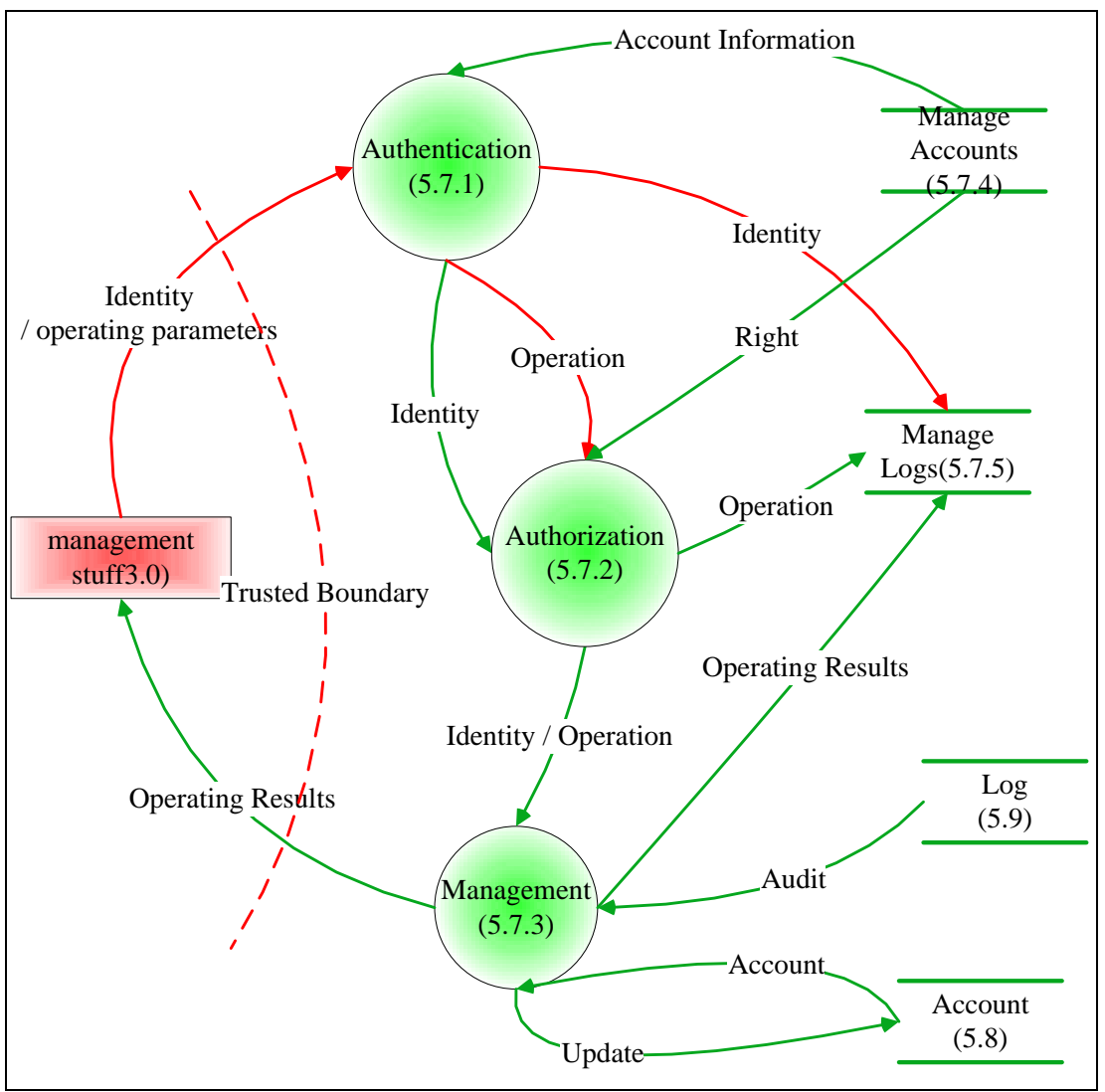

Figure 8. System Management Process 


\section{Analysis of the Online Banking Threat based on STRIDE Model}

STRIDE [3, 4] model derive from an acronym for the following six threat categories: Spoofing Identity, the illegal use of another user authentication information. Tampering with Data, a maliciously modified data. Repudiation, users refuse to engage in activities, and there is no way to prove he was repudiation. Information Disclosure, information is exposed to the access to it is not allowed. Denial of Service, refuses to the legitimate user service. Elevation of Privilege, no privileged user access privileges, so as to have enough ability to damage or destroy the entire system. By considering threats of these various categories for each single element in the DFD, STRIDE greatly supports the identification of threats within the application.

This section will be based on online banking system data flow analysis as the foundation, analysis of whether each data flow and its associated asset information is vulnerable to any type of S, T, R, I, D and E threat, threat model to construct the entire online banking system.

\subsection{Security Hypothesis}

Hypothesis 1: Suppose that the bank internal network environment is a secure environment, which has a relatively perfect management system and secure mechanism.

Hypothesis 2: Suppose that the components of the online banking system can satisfy function as they claim.

\subsection{Analysis of Online Banking External Interactor Threats}

This paper aims at the threat analysis of the online banking system, including external interactor, the data flow and the data storage involved in 7 types of key business operations, rather than each a separate analysis of operations [8]. The external interactor threat analysis 1 st and 2nd directory are shown in Table 2.

Table 2. External Interactor Threat Analysis

\begin{tabular}{|c|c|c|c|}
\hline \multirow{2}{*}{ Threat } & \multicolumn{3}{|c|}{ External interactor } \\
\hline & Online banking client (1.0) & The B2B/B2C system (2.0) & Manage staff (3.0) \\
\hline $\begin{array}{c}\text { S } \\
\text { (Spoofing } \\
\text { Identity) }\end{array}$ & $\begin{array}{l}\text { S1 Counterfeit other user identity } \\
\text { S1.1 Illegally obtained certificate } \\
\text { S1.1.1 Legal certificates obtained by } \\
\text { the attacker } \\
\text { S1.1.2 Forged certificate } \\
\text { S1.2 Certification unsecure } \\
\text { S1.2.1 Lack of authentication } \\
\text { mechanisms } \\
\text { S1.2.2 Certification is not sufficient } \\
\text { S1.2.3 Server's authentication } \\
\text { vulnerability, which can be bypassed } \\
\text { S1.2.4 Authentication algorithm } \\
\text { unsecure leading Man-in-the-Middle } \\
\text { attack process is re- } \\
\text { S1.2.5 Certification pron } \\
\text { executed S1.2.6 Passwords be cracked } \\
\text { S1.3 Password Security } \\
\text { S1.3.1 Password strength is } \\
\text { insufficient, can be cracked } \\
\text { S1.3.2 Default password is insecure }\end{array}$ & 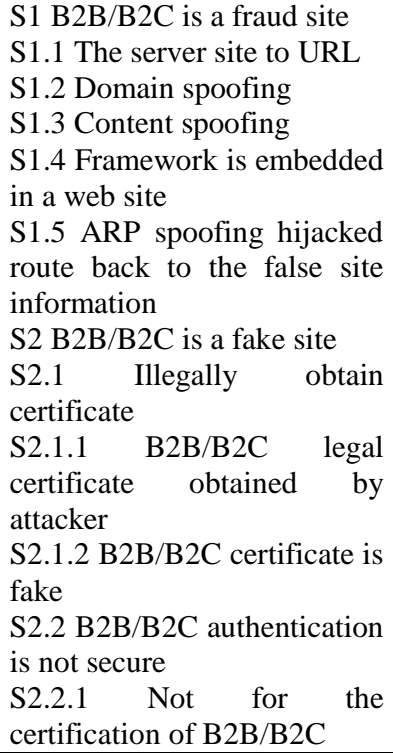 & $\begin{array}{l}\text { S1 Forged managers } \\
\text { identity } \\
\text { S1.1 Obtain certificate } \\
\text { illegally } \\
\text { S1.1.1 Administrators } \\
\text { legal certification } \\
\text { obtained by attackers } \\
\text { S1.1.2 } \\
\text { certificate } \\
\text { S1.2 Authentication is } \\
\text { unsecure } \\
\text { S1.2.1 Administrator } \\
\text { authentication } \\
\text { insufficient } \\
\text { S1.2.2 No administrator } \\
\text { authentication } \\
\text { S2 Management host is } \\
\text { counterfeit operation } \\
\text { after being invaded }\end{array}$ \\
\hline
\end{tabular}




\begin{tabular}{|c|c|c|c|}
\hline & $\begin{array}{l}\text { S1.3.3 Password storage is not secure } \\
\text { S1.4 Brute force } \\
\text { S1.4.1 Lack of mechanism to resist } \\
\text { brute force } \\
\text { S1.4.2 Mechanism of resistance to } \\
\text { brute force can be bypassed } \\
\text { S1.5 Session mechanism is not perfect } \\
\text { S1.5.1 Lack of session timeout } \\
\text { mechanism } \\
\text { S1.5.2 Lack of session state } \\
\text { examination } \\
\text { S2 Counterfeit client identity } \\
\text { communication } \\
\text { S2.1 Malware simulate keyboard } \\
\text { actions } \\
\text { S2.2 Malware simulate client sending } \\
\text { message } \\
\text { S2.3 Malware fake user's operation }\end{array}$ & $\begin{array}{ll}\mathrm{S} 2.2 .2 & \mathrm{~B} 2 \mathrm{~B} / \mathrm{B} 2 \mathrm{C} \\
\text { authentication } & \text { is not } \\
\text { sufficient } & \end{array}$ & \\
\hline $\begin{array}{l}\mathrm{T} \\
\text { (Tampering } \\
\text { with Data) }\end{array}$ & $\begin{array}{l}\text { T1 Client is embedded malicious } \\
\text { program } \\
\text { T1.1 Malware tampered the user } \\
\text { request data or the server returns data } \\
\text { T1.2 The data of malware tampered } \\
\text { with user input } \\
\text { T1.3 Malware modify browser } \\
\text { memory } \\
\text { T1.4 Malware to modify the message } \\
\text { sent or received } \\
\text { T1.5 Malware display data by user } \\
\text { actions in the interface } \\
\text { T1.6 Malware modify keyboard input }\end{array}$ & $\begin{array}{ll}\text { T1 B2B/B2C site } & \text { is } \\
\text { embedded malware } & \\
\text { T2 B2B/B2C site } & \text { is } \\
\text { controlled by attacker } & \end{array}$ & \\
\hline $\begin{array}{c}\mathrm{R} \\
\text { Repudiation }\end{array}$ & $\begin{array}{l}\mathrm{R} 1 \text { Users deny carried out transactions } \\
\mathrm{R} 1.1 \text { Lack of transaction signature } \\
\text { mechanism } \\
\mathrm{R} 1.2 \text { Log record is not perfect } \\
\mathrm{R} 1.2 .1 \text { No log records } \\
\mathrm{R} 1.2 .2 \text { Log records inadequate }\end{array}$ & $\begin{array}{l}\mathrm{R} 1 \mathrm{~B} 2 \mathrm{~B} / \mathrm{B} 2 \mathrm{C} \text { business party } \\
\text { deny carried out transaction } \\
\mathrm{R} 1.1 \text { No valid signature } \\
\mathrm{R} 1.2 \text { Log record is not } \\
\text { perfect } \\
\mathrm{R} 1.2 .1 \text { No } \log \text { records } \\
\mathrm{R} 1.2 .2 \text { Log records } \\
\text { inadequate }\end{array}$ & $\begin{array}{l}\text { R1 Executives deny } \\
\text { operation } \\
\text { R1.1 No valid signature } \\
\text { R1.2 record is not } \\
\text { perfect } \\
\text { R1.2.1 No log records } \\
\text { R1.2.2 Log records } \\
\text { inadequate }\end{array}$ \\
\hline $\begin{array}{c}\text { I } \\
\text { (Information } \\
\text { Disclosure) }\end{array}$ & $\begin{array}{l}\text { I1 Malware to steal user sensitive } \\
\text { information, such as passwords, } \\
\text { certificate, and input } \\
\text { I1.1 Malware to steal passwords and } \\
\text { other sensitive information via the } \\
\text { keyboard record } \\
\text { I1.2 Malware to obtain sensitive } \\
\text { information such as user password by } \\
\text { screenshots } \\
\text { I1.3 Malware to steal the browser data } \\
\text { in memory } \\
\text { I2 Sensitive information without } \\
\text { secure handling } \\
\text { I2.1 Sensitive information stored in } \\
\text { the local lead to information leakage } \\
\text { I2.2 Encryption key is stored on the } \\
\text { client } \\
\text { I2.3 Used client temporary files does } \\
\text { not be deleted in time } \\
\text { I3 Fake site to cheat user input } \\
\text { I3.1 User is fished }\end{array}$ & & \\
\hline
\end{tabular}




\begin{tabular}{|c|c|c|c|}
\hline & $\begin{array}{l}\text { I4 Security mechanism is not perfect } \\
\text { I4.1No message security mechanism } \\
\text { I4.2Weak message security } \\
\text { mechanism } \\
\text { I4.3 No channel security mechanism }\end{array}$ & & \\
\hline $\begin{array}{c}\mathrm{D} \\
\text { (Denial of } \\
\text { Service) }\end{array}$ & $\begin{array}{l}\text { D1 Channel overload, leading log } \\
\text { processing hang or crash } \\
\text { D1.1 Abnormal parameters lead to a } \\
\text { large number of consumption of server } \\
\text { memory or CPU } \\
\text { D1.2 Abnormal parameters cause the } \\
\text { server to a business is to hang or crash } \\
\text { D1.3 Multiple concurrent operations } \\
\text { cause the server is not responding } \\
\text { D1.4 SYN FLOOD/HTTP FLOOD } \\
\text { attack } \\
\text { D1.5 Large number of network packet } \\
\text { blocking network } \\
\text { D2 Undermine message integrity }\end{array}$ & $\begin{array}{l}\text { D1 Channel overload, } \\
\text { leading log processing hang } \\
\text { or crash } \\
\text { D1.1 Abnormal parameters } \\
\text { lead to a large number of } \\
\text { consumption of server } \\
\text { memory or CPU } \\
\text { D1.2 Abnormal parameters } \\
\text { cause the server to a business } \\
\text { is to hang or crash } \\
\text { D1.3 multiple concurrent } \\
\text { operations cause the server is } \\
\text { not responding } \\
\text { D1.4 SYN FLOOD/HTTP } \\
\text { FLOOD attack } \\
\text { D1.5 large number of } \\
\text { network packet blocking } \\
\text { network } \\
\text { D2 failure message integrity }\end{array}$ & $\begin{array}{l}\text { D1 Channel overload, } \\
\text { leading to hang or crash } \\
\text { log processing } \\
\text { D1.1 Abnormal } \\
\text { parameters lead to a } \\
\text { large number of } \\
\text { consumption of server } \\
\text { memory or CPU } \\
\text { D1.2 Abnormal } \\
\text { parameters cause the } \\
\text { server to a business is to } \\
\text { hang or crash } \\
\text { D1.3 multiple } \\
\text { concurrent operations } \\
\text { cause the server is not } \\
\text { responding } \\
\text { D1.4 SYN FLOOD/ } \\
\text { HTTP FLOOD attack } \\
\text { D1.5 Large number of } \\
\text { network packet } \\
\text { blocking network } \\
\text { D2 Server data has } \\
\text { physical damage or } \\
\text { destruction Host unstable, } \\
\text { D3 Host } \\
\text { which causes data errors }\end{array}$ \\
\hline $\begin{array}{c}\mathrm{E} \\
\text { (Privilege } \\
\text { Escalation) }\end{array}$ & $\begin{array}{l}\text { E1 Client security vulnerabilities } \\
\text { E1.1 Client control of security } \\
\text { vulnerabilities, leading to hanging } \\
\text { horse } \\
\text { E1.2 Client system kernel driver of } \\
\text { security vulnerabilities } \\
\text { E1.3 Client components of security } \\
\text { vulnerabilities, leading to a remote } \\
\text { attack } \\
\text { E1.4 Not on the client control } \\
\text { authority to define arbitrary, leading to } \\
\text { read and write files } \\
\text { E1.5 Cross-domain attack } \\
\text { E2 The server security vulnerabilities } \\
\text { E2.1 The server has cross-site } \\
\text { scripting vulnerabilities }\end{array}$ & & \\
\hline
\end{tabular}

\section{The Construction of Threat Tree}

Threat tree $[4,7,8]$ provides a formal and systematic method for the analysis of system threat. Typically, modeling all threats of a system is very complex. Therefore, all threats with a single threat tree to system modeling is not realistic, since the threat tree will be very large. Based on the above reasons, this paper considers the STRIDE threat model and the threat tree analysis together. Firstly, according to the STRIDE model, we divide system threat into five aspects: S, T, R, I, D, E, so there are corresponding threats target in every aspects (see Table 2 ). Then using the threat tree threat analysis on each aspect of threat category, we can reduce the complexity of threat tree structure greatly. 


\subsection{Logic Relationship of Threat Tree}

A threat tree models threats by organizing threat actions hierarchically, that is, it is a data structure contains nodes which are hierarchically connected by directional edges. When be represented by text, a threat tree can be expressed by threats and the relationship "AND (conjunction)" and "OR (disjunction)".

\subsection{Construction of Threat Tree}

Analysis of potential threats in the online banking system, and decompose the attack mode which threat tree may face, the basic method is as following:

1. Classify online banking security threats by using the STRIDE threat model.

2. From the attack mode to determine the threat of these themes, decompose gradually, and then form the middle layer nodes. For example, the top-down analysis of attack pattern.

3. Check the child nodes to determine the need for further decomposition, if necessary, make the child nodes as the current target, repeat the above steps, and break them down into smaller modules.

When the node cannot be decomposed, terminate the decomposition process, i. built an inverted threat tree. At this time, all the leaf nodes are independent of each other, and also can be assessed components.

This paper only gives online banking client fake threat tree as an example (Figure 9).

OR 1 Counterfeit other users' identity

OR 1.1 Illegally obtain certificate

OR 1.1.1 Legal certificate obtained by attacker

1.1.2 Forged certificate

1.2 Unsecure certification

OR 1.2.1 Lack of authentication mechanisms

1.2.2 Certification is insufficient

1.2.3 Server s' authentication vulnerability, which can be bypassed

1.2.4 Authentication algorithm is unsecure, leading man-in-middle attack

1.2.5 Certification process is re-executed

1.3 Cracked passwords

OR 1.3.1 Password Security

1.3.1.1 Password strength is insufficient, which can be cracked

1.3.1.2 Unsecure default password

1.3.1.3 Unsecure password storage

AND 1.3.2 Brute force

OR 1.3.2.1 Lack of mechanism to resist brute force

1.3.2.2 Mechanisms to resist brute force can be bypassed

1.4 Session mechanism is not perfect

OR 1.4.1 Lack of session timeout mechanism

1.4.2 Lack of session state check

2 Communication with forged client identity

OR 2.1 Malwares simulate keyboard to launched operation

2.2 Malwares simulate client to send packets

2.3 Malwares counterfeit user initiate operation

Figure 9. Online Banking Client Fake Threat Tree 
To the online banking system, a threat tree is a set of all the threats it is facing. Thus, any threat in the threat tree may be a security risk of the online banking system. The detailed analysis of an external entity can see in the 2 nd and 3rd directory of table 2 .

\section{Conclusions}

Threat modeling can help system security evaluators understand the system threats may face, and can grasp the vulnerability that the threat could exploit, and it also enable evaluators seek purposefully vulnerabilities and risks in the field testing so as to find attack paths quickly and efficiently in penetration testing.

Threat tree is a system threat modeling tool with tree representation structure, it has the advantages of structured and reusable. However, the present studies are lack of systematic and holistic in the use of threat tree system threat analysis, thus it is difficult to carry out effective use of threat tree. This paper combines STRIDE threat model with the threat tree analysis, greatly reducing the threat tree constructed complexity, making it easier to use and maintain the threat tree. Through the threat analysis of online banking system, this method can well describe the online banking system security threats, and can provide guidance for system security analysis and evaluation.

\section{Acknowledgements}

I am grateful to Mr. Zhang $\mathrm{Li}$, the director of information system risk evaluation department of China Information Technology Security Evaluation Center. His knowledge and support has led to innumerable improvements of this paper. Thanks are also due to a number of my colleagues who generously read the paper entirety and to give me the benefit of their tremendous suggestions. Each of them deserves credit for the quality and style of this paper.

\section{References}

[1] C. Joris, D. Valentin and D. Danny, "On the Security of Today's Online banking Systems", Computers \& Security, vol. 3, no. 21, (2002).

[2] R. Nigel, "Securing online banking”, Card Technology Today, vol. 10, no. 17, (2005).

[3] S. Hernan, S. Lambert, T. Ostwald and A. Shostack, "Uncover Security Design Flaws Using The STRIDE Approach”, MSDN Magazine, (2006).

[4] H. Michael and L. David, "Writing secure code: practical strategies and proven techniques for building secure applications in a networked world", Microsoft Press Corp, WA, (2002).

[5] W. Stallings, "Cryptography and Network Security - Principles and Practices", Upper Saddle River, Pearson Education International, Upper Saddle River, New Jersey, (2006), pp. 9-11.

[6] C. Möckel and A. E. Abdallah, "Threat modeling approaches and tools for securing architectural designs of an e-banking application", 2010 Sixth International Conference on Information Assurance and Security, Atlanta, USA, (2010) August 23-25.

[7] M. Ikuya and Y. Yamaoka, "Threat tree templates to ease difficulties in threat modeling", Proceedings 2011 International Conference on Network-Based Information Systems, Tirana, Albania, (2011) September 7-9.

[8] Threat Risk Modeling. Open Web Application Security Project (OWASP), http://www.owasp.org/ index.php/ Threat_Risk_Modeling. 


\section{Authors}

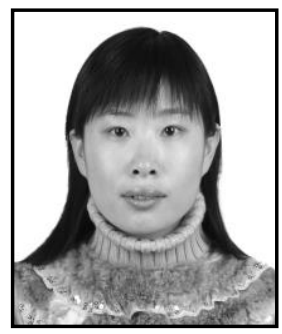

Tong Xin, she received the Ph.D. degree in information security from Beijing University of Posts and Telecommunications University in 2008. She is Associate Researcher of information system risk evaluation department of China Information Technology Security Evaluation Center. Her scientific research direction: information system risk assessment and communication security.

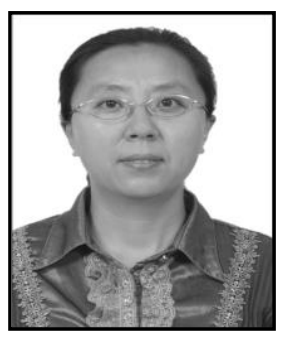

Ban Xiaofang, she is the vice director of information system risk evaluation department of China Information Technology Security Evaluation Center. She has very rich practical experience on information system security risk assessment. Her scientific research direction: network security and information system risk assessment. 